\title{
THE UMBRELLA BIRD
}

\author{
BY \\ IEE S. CRANDALL \\ New York
}

When Charles Cordier arrived from Costa Rica on October 9, 1942, bringing with him, among other great rarities, three Bare-necked Umbrella Birds (Cephalopterus ornatus glabricollis), it seemed to us that the mere possession of such fabulous creatures was satisfaction enough. True, they were not beautiful - some realists have even gone so far as to name them "ugly" - and like all Cotingas, they were definitely dull. But in spite of all, they really were Umbrella Birds and if we could solve the problem of their long term requirements, they must reveal to us much that had been unknown. For only once before, as far as we can learn, has an Umbrella Bird been kept in captivity in either Europe or North America. According to a note by Frank FINN in 'Avicultural Magazine' for October, 1909, this was a young bird owned in England by Mr. H. C. Molineaux, a private aviculturist. Nothing beyond the arrival of the bird is, recorded.

With nothing whatever to guide us, beyond CoRdier's brief experience, we put the adult male and the female together in one cage and an immature male in another. The cages seemed large enough and both wre planted with small palms for shelter. For a year, nothing in particular happened. All of the birds remained dull and quiet, and although we pointed them out frequently on personally-conducted tours, it was difficult to convince visitors that Umbrella Birds are something of special interest. Then we noticed that the young male was fading and in spite of all we could do, he became rapidly weaker until his death. A post mortem by Doctor Goss showed a necrotic mass of undeterminable nature in the thorax. This was better, at least, than malnutrition, and we were stimulated to greater efforts with the remaining pair.

When the big planted cage in the south hall of the Bird House, known as the Tropical Rain Forest, was reconditioned in the autumn of 1944, we looked about for birds to people it. First of all, of course, we would try again with the Umbrella Birds. It just might suit them.

From the very first, the experiment was a success. The birds agreed perfectly, with no quarreling or interference. The Umbrella Birds liked it - we could see that from the beginning. And it was high time they found something they liked, for they were deep in moult and needed to settle down if they were to feather properly. They finished their change of plumage rapidly and soon 


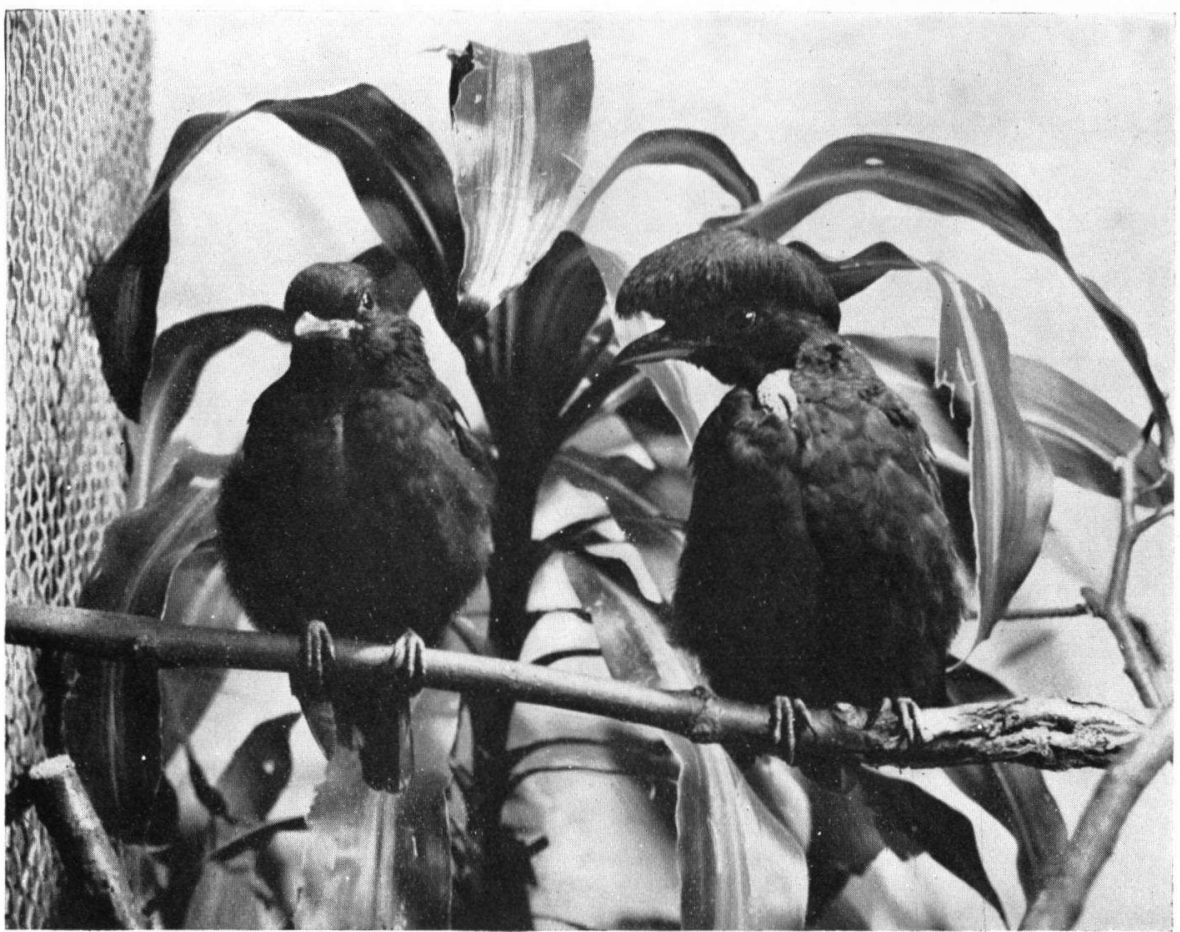

When the male Umbrella Bird (at right) is out of breeding condition, the bare, red throat area is greatly contracted and gives little promise of the enormous proportions it will bear later when inflated. This is the pair of Umbrella Birds, shortly after arrival and before they had really settled down.

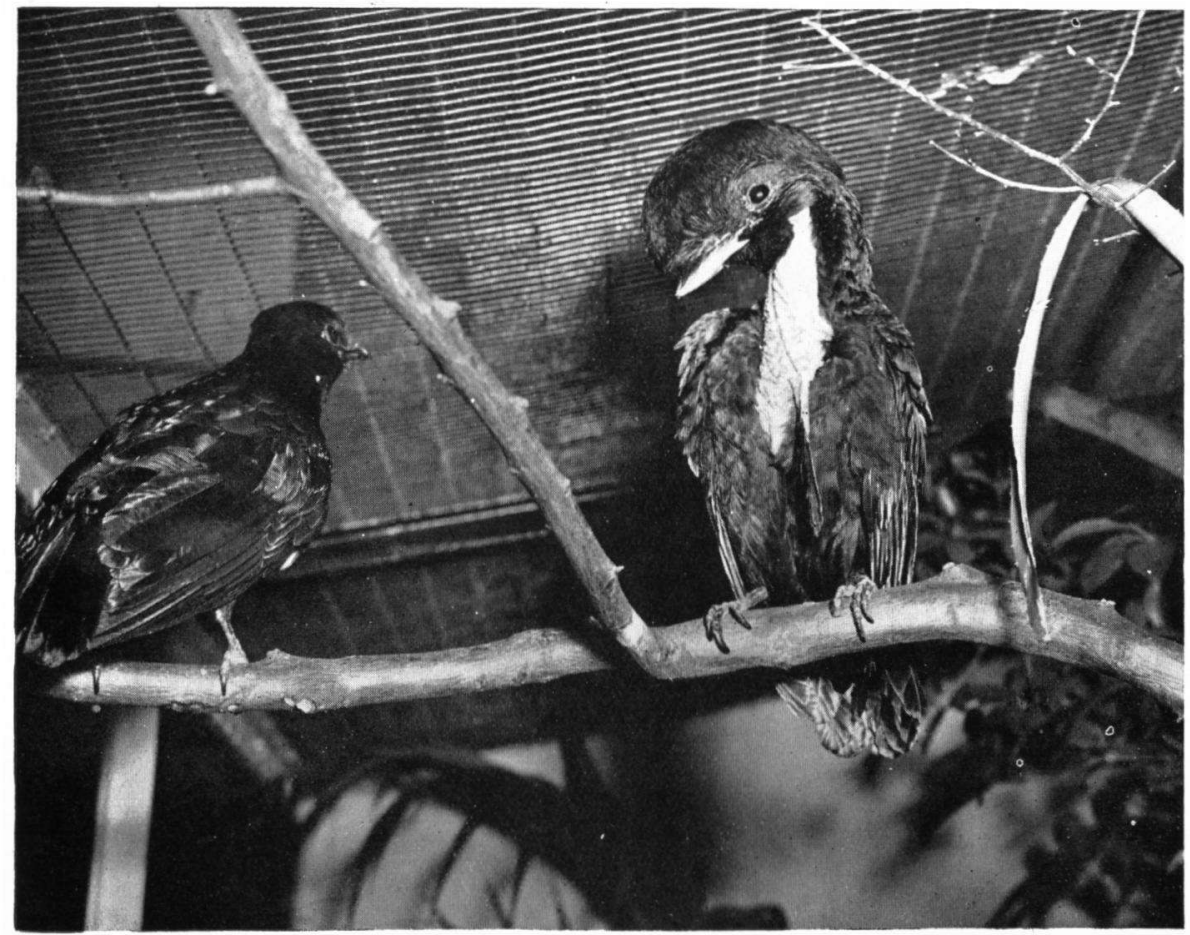

The contrast with the photograph at the top of this page is apparent in this picture, made this spring when the Umbrella Bird was at the height of its display. Even the tiny, feather-tipped "pig tail" at the bottom of the throat area can be seen. The far less spectacular female Umbrella Bird is at the left. 


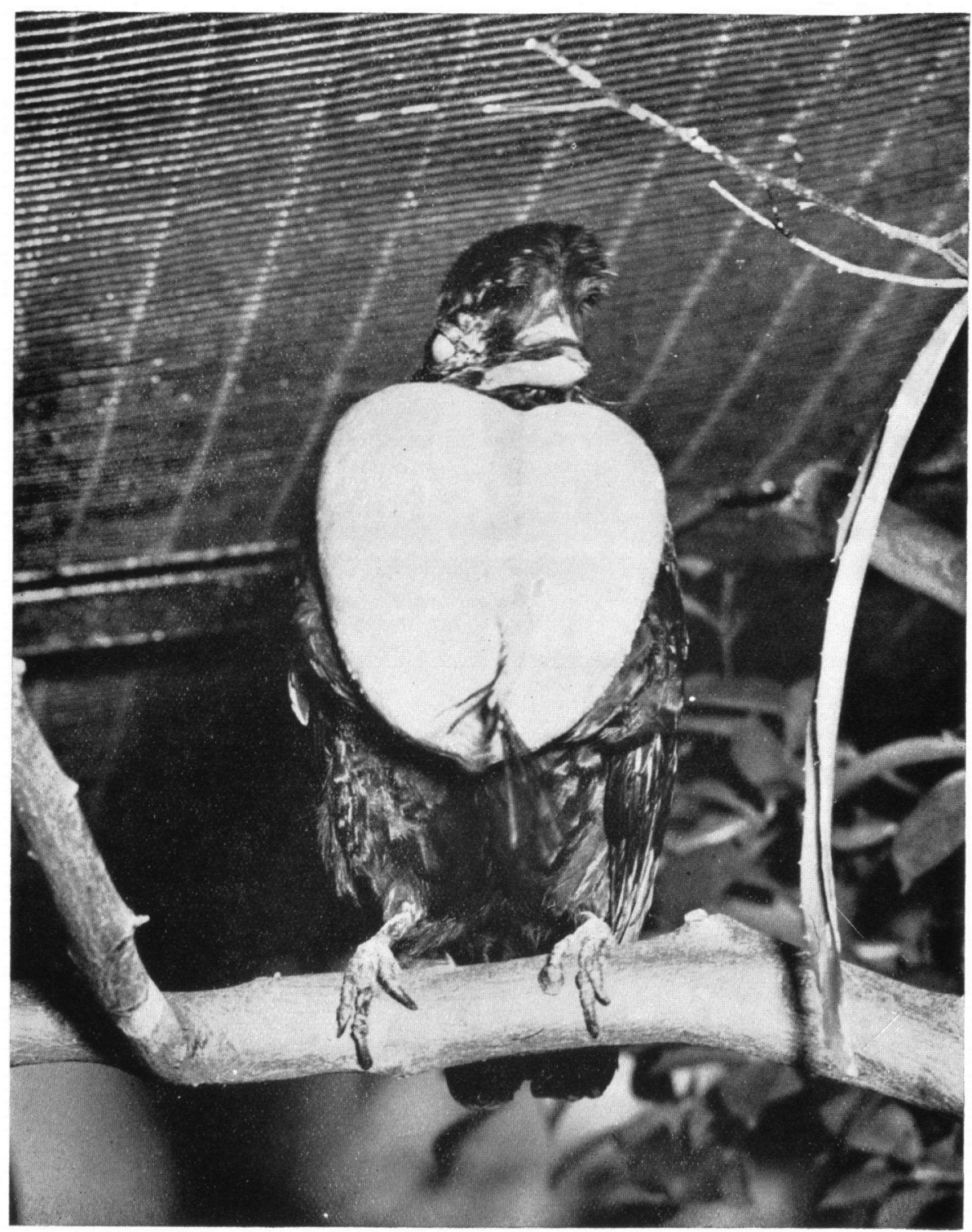

At the peak of display. Here the male Umbrella Bird has inflated his air sac fully until it is "as large as a tomato", as Charles CoRuter described it after seeing the display in the forests of Costa Rica. Even distended in this way, the bare skin remains bright red. The fleshy tassel near the lower part of the sac has grown from a three-quarter-inch spike of skin to a length of almost three inches, and when the bird moves his head from side to side rapidly, the tassel will gyrate like the pendulum of a runaway clock. 
began to look like real Umbrella Birds. Their black feathers were smooth and shining, their great dark eyes were bright. The "umbrella" of the male was rounded and full, and while sometimes it stood up stiff and straight in front like a well-cut pompadour, if often fell forward, so completely relaxed that it fully covered the great crow-like bill.

Winter passed, and with the first days of spring there were rumors that the Umbrella Bird was playing antics of a sort. I thought at once of CoRDiER's piece in 'Animal Kingdom' for January-February, I943 - certainly one of the very best we have ever printed. He called it "The Umbrella Bird Comes to the Zoo" and in it he reported, among other observations, concerning the courtship display of this little known species. I hunted out the piece and checked it with care. With some idea of what to expect, I began spending noon hours in front of the Tropical Rain Forest. And I had not long to wait. On March 30, 1945, to be exact, I witnessed the full spectacle. On subsequent numerous occasions, I was able to add a few minor details.

Since mid-winter, the bare skin on the throat of the male had been expanding and deepening the intensity of its scarlet. At the beginning of the display, this brilliant patch spread slightly, laterally, so that there was a sharp contrast against the deep black of head and neck. It was also extended downward, with a distension as large as a pigeon egg at the very bottom.

There are two distinct display forms. In the first, the bird turns his head forward and down, gasps, and distends his air sack to the size and shape of a scarlet goose egg, big end down. The fleshy tassel, tipped with scraggly feathers and ordinarily about three-quarters of an inch in length, is seen to have lengthened to quite three inches, although its diameter is hardly greater. Then the head is moved rapidly from side to side, making the tassel gyrate wildly, like a pendulum out of time with its clock. During this performance, the bird utters a soft "br-r-r-r," which I think CoRdien refers to when he says it sounds like a distant jaguar. I suppose, in the forest, it might.

In the second form of display, the force of the expansion is forward rather than downward. There is the same pigeon's egg at the bottom to begin with, but this time.the bird stands upright, his crest doing a tight pompadour. Suddenly, he snaps his head forward, dropping the spread umbrella so that the bill is enterely covered. He then jerks upright again and extends his air sac until he looks like a brilliant toy balloon and nearly as perfectly spherical. Now he throuws his head sharply backward, making the tassel fly violently in and out, in the axis of his body. At the same time, he gives fort a loud "plunk", which Cordier calls a "boom". After several of these violent convulsions, the air is expelled, with no sound.

It is pleasant to have so full a confirmation of what Cordier saw in the jungles of Costa Rica. And it is pleasant to know that the Umbrella Bird is far from being the dull creature we had thought him. 